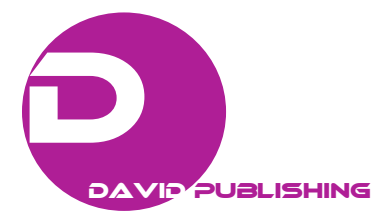

\title{
Design and Development of a Multi-functional Laparoscopic Device
}

\author{
Tugrul Tansug ${ }^{1}$, Elif Taskin ${ }^{2}$, Eray Kurt ${ }^{2}$ and Meltem Elitas ${ }^{2}$ \\ 1. General Surgeon, Adatip Istanbul Private Hospital, Istanbul 34912, Turkey \\ 2. Mechatronics Program, Faculty of Engineering and Natural Sciences, Istanbul 34956, Turkey
}

\begin{abstract}
This study presents a design of a multifunctional laparoscopic appendectomy device that includes three surgical instruments commonly used in laparoscopic appendicitis surgeries: endoloop, endobag and scissors. It collects these three independent surgical tools in a single laparoscopic appendectomy device. These days there is a trend of moving to multi-functional surgery devices during minimally invasive surgery. The main reasons behind the minimal invasive surgery are to avoid changing the devices several times during the operation, to reduce the time spent in operation, to increase the efficiency of the operation, to facilitate the follow-up of the camera and devices, and to leave trocars to be used for other surgical instruments. The multi-functional appendectomy device that, we present here, provides these benefits. The standard trocar entries are appropriate for its usage. The presented multifunctional laparoscopic appendectomy device offers more practical use in comparison to individual devices. On the other hand, development of these multi-functional surgery devices can be directly enhanced to the robotic surgery devices.
\end{abstract}

Key words: Apendectomy, multi-functional, laparoscopy, SolidWorks, surgery.

\section{Introduction}

Laparoscopic surgery, also referred to as minimally invasive surgery, was first used during the middle of 1980s. After that time, it was spread out all around the world due to its advantages. First laparoscopic surgery started with cholecystectomy operation (What is laparoscopic surgery, 2002). Later these operations, their results were found more effective when surgeons compared them with the open surgeries' results. Therefore, new tools and methods were started to improve by surgeons and engineers. Thus, laparoscopic surgical methods get very popular. As a result, procedure of these operations started to change.

A video camera and several instruments are an assistance of laparoscopic surgery, which describes the performance of surgical procedures. During the surgical procedure, small cuts that are the size of 1-1.5 $\mathrm{mm}$ diameter are made and plastic tubes, which are

Corresponding author: Meltem Elitas, $\mathrm{PhD}$, associate professor, research fields: surgical tools, microfluidic devices, quantitative biology and medicine. called ports, are placed through these incisions. Secondly, the camera is plugged into patient body because; it helps to transmit images of the organs onto a monitor which looks at during the operation (da Vinci Surgery, 2017).

Thus, surgeon cannot see the patient's organ without large scars. As a result, the camera, which is transmitted into patient's body, becomes the eyes of a surgeon during the operation (Kalkan, Z. 2017, Kim, S. 2015). The instruments are introduced through the ports that allow access to the operation area inside the patient. In conclusion, the operation begins and finishes with small scars (Laparoscopic Appendectomy Review, 2017).

One of the most commonly performed surgeries has been laparoscopic cholecystectomy. However, in this research, we focused on appendectomy operations and tried to create a multifunctional operation device for the appendectomy related surgeries.

In humans, the appendix is small and has no known function. However, sometimes, wasted material can occlude in it and appendectomic operations have been 
essential (Üstün, 2011). Before surgeon starts the appendectomic operation, $\mathrm{CO}_{2}$ gases are added into patient abdominal area. This method helps the surgeon to clearly monitor the area where the selected organ stands through the monitor. Afterwards, the small incisions are made to create ports where the instruments are inserted into patient's body.

With the help of the camera (laparscope), surgeon maintains the operations. In the appendectomy, surgeon starts with the operation to remove connective tissue surrounding the appendix. The surgeon isolates the appendix using scissors or ligasure. Next, the scissor is removed from the operation area via the port and an endoloop is inserted into the patient's body. The endoloop holds and tightens the connection between the appendix and ileum. Afterwards, the surgeon cuts the appendix and puts it into an endobag, which carries the appendix, and takes it out from the patient's body.

In the appendix surgeries, changing instruments frequently create some complications for surgeons. Therefore, we decided to design a multifunctional surgical tool for appendectomy operations. This tool is a combination of 3 different instruments, which are commonly used for the appendectomy operations. These instruments are endoloop, endobagand scissors (Frecker, Schadler, Haluck, Culkar, \&Dziedzic, 2005). Our proposed device uses only one port and after gets into the patient's body, there is no need to replace the laparascopic tools several times. As a result, it creates free trocars for other instruments. Similarly, while surgeon takes an instrument out and plugs a new one, loss of time during the operation occurred since, surgeon has to re-coordinate the way which tool is going to follow. Additionally, our proposed device provides a stable operation condition for the surgeon and helps to improve her/his concentration.

One of the biggest advantages of laparoscopic surgeries is recovery time of the post-operative period which is rapid in comparison to open surgeries (Kim,
2015). Hence, small cuts tend to be painless and patient can rapidly recover after the operation. Similarly, cosmetic results of the laparoscopic surgery are marvelous since it does not create big scars after operations. Additionally, this kind of surgery reduces the risk of the infections; it leads to early return to work and normal physiology for daily life. More importantly, all holes are made between fibers so, there is no cut in the muscle (Kim, 2015). Thanks to its multifunctional features, surgeons become less tired at the end of the operations and create more stable work environment and operations process.

\section{Materials and Methods}

We designed the multifunctional laparoscopic device using the SolidWorks 2015, a 3-dimensional (3D) design program. Standard dimensions of all instruments are integrated into new device, in Fig. 1.
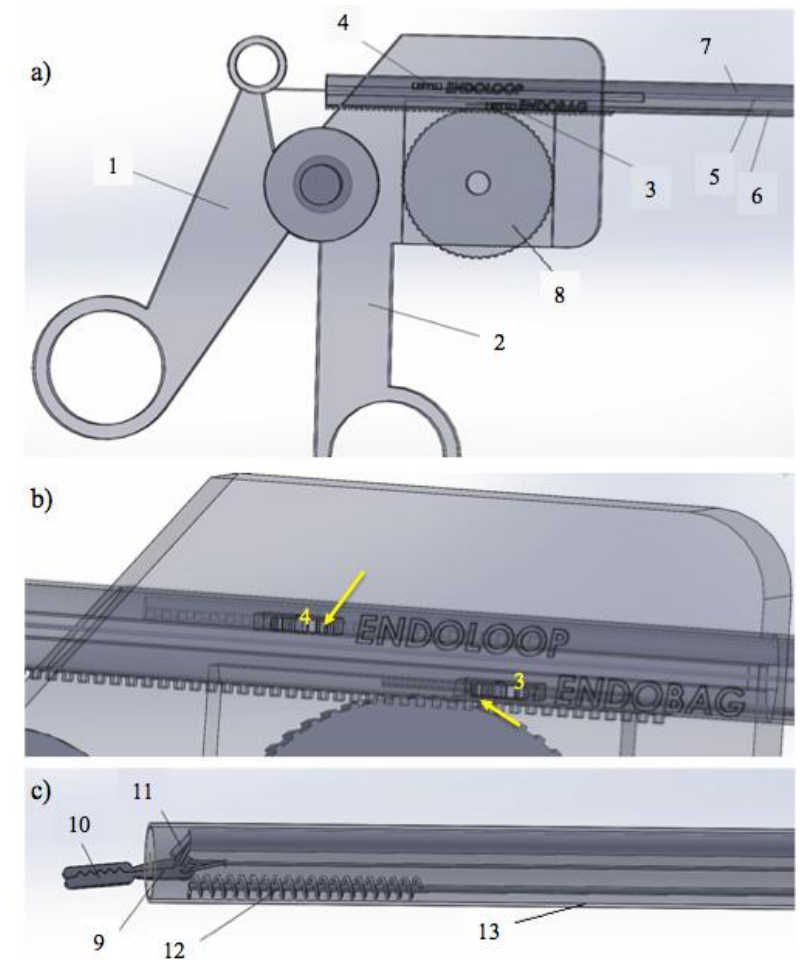

Fig. 1 The multi-functional laparoscopic device.

1-holding area for scissors; 2-main component; 3-gear which helps to push the bag out; 4-gear which helps the endoloop out; 5-scissors tools; 6- endobag part; 7-endoloop part; 8-main gear; 9-shap scissors; 10-holding scissors; 11-endoloop; 12 - endobag; 13 - outside layer. 
The device consists of three pars including an endloop, an endobag and a scissors. These instruments have different duties during the operation; the endoloop separates small bowel and appendix, the endobag covers the appendix and helps to remove it without contamination into the body, while the scissors cut the appendix when it is separated by the endoloop inside the endobag.

Table 1 shows the dimensions of the instruments, which are assembled, in a single laparoscopic device.

Thanks to multifunctional laparoscopic device, it used only $1.2 \mathrm{~cm}$ diameter and $53 \mathrm{~cm}$ length sheath to cover whole laparoscopic instruments together (Fig. 2). As a result of this process, the operation is done by one trocar, other ports become free for other laparoscopic instruments. Therefore, it reduces the number of instruments that are used in surgery.

Fig. 3 illustrates the gear mechanism of the device. First, the ligasure and scissors are pushed out through movement of main gear to separate small bowel from

Table 1 Dimension and length of the instruments.

\begin{tabular}{ll}
\hline Tools & Diameter $(\mathrm{cm}) /$ length $(\mathrm{cm})$ \\
\hline Endoloop & $0.3 / 47$ \\
Endobag & $0.3 / 47$ \\
Scissors & None $/ 50$ \\
Trocar & $1 / 0$ \\
\hline
\end{tabular}

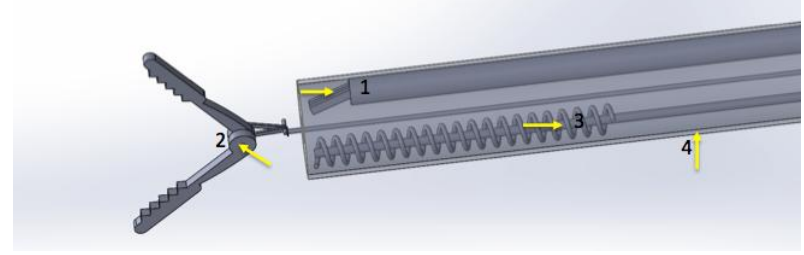

Fig. 2 The multi-functional laparoscopic device. 1—endoloop; 2-scissors; 3 - endobag; 4-sheath.

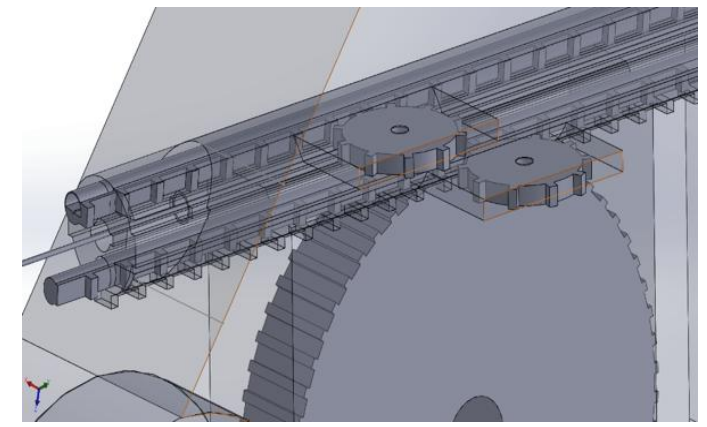

Fig. 3 The gear mechanism of the device.

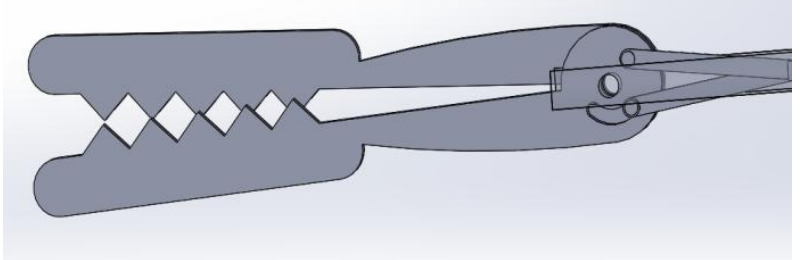

Fig. 4 Thescissors mechanism of the device.

adipose tissue and vessels. Afterwards the ligasure and scissors are drawn back through reverse direction movement of main gear. Then, the rigid rod that carries the node is taken out and wafted to connection point of appendix and small bowel. Next, it is knotted. The main reason for this process is preventing bleeding or inflections in abdominal cavity. After this process ends, the rigid rod is retracted to main sheath through the movement of gear. Following that, endobag is taken out through the movement of its gear and it covers the appendix. Afterwards the main sheath is moved back again and the sharp part of scissors is revealed. Scissors cut the appendix and it is taken out from human body with the device.

The suggested system is effective, easy to use. Also, device is single use and budget friendly based on the materials that are used in production of device.

Another advantage of this device is having different kinds of scissors' mechanism. Fig. 4 represents the mechanism of scissors. The part which is connected to the main body is sharp, while the end of the scissors is tweezers for holding tissue parts.

Another important feature about these scissors is when it is opened, it does not cover as much space as the normal scissors. As a result, this mechanism helps us to integrate other tools into our new multifunctional appendectomy device.

\section{Conclusions and Future Work}

With the developed technology, all surgical techniques and instruments are developed. For instance, surgeons can get higher quality of images from cameras day by day and operations become more effective. On the other hand, laparoscopic operations 
have some shortcomings. During these operations, surgeons use the tools rather than their hands. As a result, the sensation of feeling of tissues gets harder when we compare it with the traditional operations (Hunter, 2007). Similarly, laparoscopic surgeries cause to be harder movements of writs due to long laparoscopic instruments.

When people consider these kinds of shortcomings, the aims of developing more sensitive and practical tools become the top of the agenda in today's world (Rosser \& Savalgi, 1997). Ever since then, the use of laparoscopic instruments and methods has greatly improved, and new use is being developed rapidly. Similarly, in this project we tried to reduce these hardships during the surgery via combining three different surgical tools.

Our future goal is to make this tool motorized for robotic-assisted surgery operations.

\section{References}

[1] “What Is Laparoscopic Surgery?" Retrieved in July 2017 from http://www.surgery.usc.edu/divisions/tumor/pancreasdiseases/ web\%20pages/laparoscopic\%20surgery/WHAT\%20IS\%20L AP\%20SURGERY.html.

[2] “da Vinci Surgery." Accessed July 10, 2017. http://www.davincisurgery.com/.

[3] Rosser, J. C., Rosser L. E., and Savalgi, R. S. 1997. "Skill Acquisition and Assessment for Laparoscopic Surgery." Arch. Surg 132: 200-4.

[4] Kalkan, Z. 2017. Laparoskopik (Kapalı Yöntem) Ameliyatların Avantajlar1. http://uzeyirkalkan.com/page/tr/90/Laparoskopik_(Kapali _Yontem)_Ameliyatlarin_Avantajlari.

[5] Kim, S. 2015. "Laparoscopy." In Healthline. http://www.healthline.com/health/laparoscopy\#overview 1.

[6] Laparoscopic Appendectomy Review (n.d.). Steady Heath. Retrieved July 16, 2017, fromhttp://ic.steadyhealth.com/laparoscopicappendectom y-review.

[7] Frecker, M. I., Schadler, J., Haluck, R. S., Culkar, K., and Dziedzic, R. 2005. "Laparoscopic Multifunctional Instruments: Design and Testing of Initial Prototypes." JSLS 9: 105-12.

[8] Hunter, P. 2007. "The Cutting Edge: A Synergy of Modern Surgical Techniques and Science Improves Patient Survival and Recovery." EMBO Reports 8: 999-1002.

[9] Üstün, M. 2011. "Laparpscopik cerrahi nedir, nasil yapilir, faydalari nelerdir, hangi ameliyatlar laparoscopic yapilabilir?" Retrieved in July 2017 from https://www.doktorsitesi.com/makale/laparoskopik-cerra hi-nedir-nasil-yapilir-faydalari-nelerdir-hangi-ameliyatlar -laparoskopik-yapilabilirhttps://www.doktorsitesi.com/m akale/laparoskopik-cerrahi-nedir. 